Portland State University

PDXScholar

7-11-2019

\title{
Introducing Cornerstone Courses into Electrical and Computer Engineering Curriculum
}

\author{
Branimir Pejcinovic \\ Portland State University, pejcinb@pdx.edu
}

Follow this and additional works at: https://pdxscholar.library.pdx.edu/ece_fac

Part of the Electrical and Computer Engineering Commons

Let us know how access to this document benefits you.

\begin{abstract}
Citation Details
Published as: B. Pejcinovic, "Introducing Cornerstone Courses into Electrical and Computer Engineering Curriculum," 2019 42nd International Convention on Information and Communication Technology, Electronics and Microelectronics (MIPRO), Opatija, Croatia, 2019, pp. 1427-1432.
\end{abstract}

This Post-Print is brought to you for free and open access. It has been accepted for inclusion in Electrical and Computer Engineering Faculty Publications and Presentations by an authorized administrator of PDXScholar. Please contact us if we can make this document more accessible: pdxscholar@pdx.edu. 


\title{
Introducing Cornerstone Courses into Electrical and Computer Engineering Curriculum
}

\author{
B. Pejcinovic* \\ ${ }^{*}$ Portland State University, Electrical and Computer Engineering dept., Portland, OR, USA \\ pejcinb@pdx.edu
}

\begin{abstract}
Almost all engineering programs have some form of final, culminating design experience, which is typically taught as a senior year capstone design course. Due to ABET requirements these are team and project based. Many programs will also have projects interspersed among required and elective courses, but these tend to be overrepresented in freshman year. We have recently introduced a set of courses during sophomore year that mimic our approach to capstone courses and provide authentic engineering design experience. These so-called cornerstone courses provide scaffolding by introducing all of the components of teamwork and design process but in a less formal and formative way. We will provide details of our goals, student learning outcomes, tools used, logistics and initial experiences.
\end{abstract}

Keywords - curriculum development; engineering education.

\section{INTRODUCTION}

Curriculum design of engineering programs is an ongoing process that has yielded many different approaches. The process itself is driven by many different factors, such as accreditation, available resources, government policies, and faculty beliefs. Currently, there are many calls for reforming, or even revolutionizing, engineering education, as well as increasing the number of engineering graduates [1]-[3]. On a practical level, however, there are many obstacles to implementation of any significant reforms.

One such obstacle is the current structure of many engineering programs. Even though there has been significant movement in reforming overall curriculum, it has mostly been focused on freshman and senior years. In the United States, latter was largely driven by ABET 2000 requirement to implement a final design experience, socalled capstone design, that all student should participate in [4]. In our electrical and computer engineering (ECE) programs we started a capstone program in late 1990-s and early 2000-s and have reported on its organization in [5]. While there are many different ways that capstone design course or courses can be implemented there is a general feeling among engineering faculty that we have figured out what goals and objectives are appropriate for capstone as well as how to set these courses up.

Another problem that has plagued engineering programs for a very long time is low retention rates in freshman years. Traditionally, freshman year in engineering programs was reserved for building up students' math and physics skills. This meant that it was usually the calculus sequence that determined retention because students would not take any engineering classes until their sophomore year. It was also observed that lack of clear application of the principles learned in math and physics led to low motivation among students and lower retention rates [6].

This problem was addressed in two primary ways:

1. Introducing engineering courses in freshman year, which typically did not have heavy math prerequisites and were intended to build student interest and motivation to study engineering.

2. Introducing different ways to teach introductory math and tying it more directly to engineering applications. One such program was started by Wright State University [6] and with support from NSF has spread to other US universities.

These are not mutually exclusive. We used ideas from the first approach when designing our freshman sequence, which starts with a gentle introduction to engineering and gradually ramps up requirements and expectations from students [7][8]. Another way to design a holistic approach to freshman introduction to engineering is "Living with the lab", which was initially developed at Louisiana Tech [9] and implemented in mechanical engineering at PSU [10].

Some programs offer so-called "cornerstone" courses, e.g., [11][12], but the majority of these seem to be freshman courses aiming to provide motivation for potential engineering students, while providing somewhat authentic design or problem solving experiences. These freshman students, however, will typically not have enough technical background to integrate various strands of electrical and computer engineering.

Much of the curriculum reform has so far focused on freshman and senior years. As noted in [2]

“... the senior year has seen notable change through capstone design experiences, which ask students to synthesize the technical knowledge, skills, and abilities they have gained with professional capacities, using reflective judgment to make decisions and communicate these effectively. However, this ideal of the senior year has not yet been fully realized, because many of the competencies required in capstone design, or required of professional engineers, are only partially introduced in the first 
year and not carried forward with significant emphasis through the sophomore and junior years."

To address this lack of emphasis on professional skills we decided to implement a pair of courses at sophomore level that would scaffold student development towards capstone projects. In sections below we will first discuss our overall curriculum, followed by description of cornerstone courses, with come observations and conclusions at the end.

\section{OVERALL ECE CURRICULUM}

In order to provide full context for our new courses, we need to first discuss overall curriculum in ECE programs at Portland State University. Our electrical and computer engineering programs are four-year programs with roughly 180 quarter-based credits required, which is usually translated as 120 semester-based credits. These are split roughly equally among lower-division coursework (freshman and sophomore courses) and upper-division coursework. A brief overview of main components: general education, math and science, and ECE specific, is given below.

\section{A. General education}

General education requirements take around $22 \%$ of total credits, as illustrated in Fig. 1. On freshman level, students take integrated sequences of courses called "Freshman Inquiry", followed by a set of courses from socalled "Sophomore Inquiry". These are meant to provide students with a solid foundation in four main areas: inquiry and critical thinking, communication, diversity, equity and social justice, and ethics and social responsibility [13]. Third component is "Junior cluster" in which students select courses from a list for a given cluster.

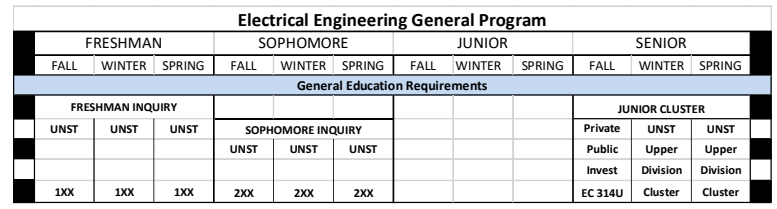

Figure 1. Outline of general education requirements in electrical engineering (EE) program at Portland State University (PSU).

\section{B. Math and Science}

Math and science requirements occupy approximately $25 \%$ of the total credit hours, as illustrated in Fig. 2. In common with many other programs, first two years are used to teach students math and science fundamentals, with only one statistics course in junior year.

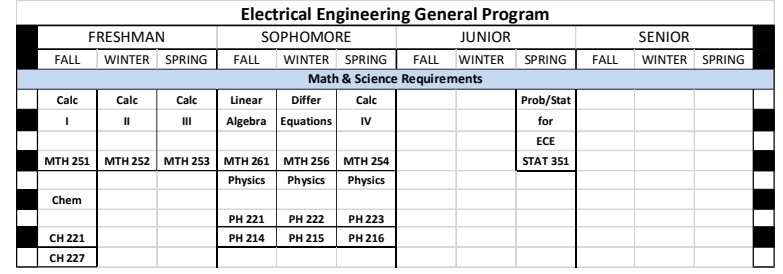

Figure 2. Outline of math and science education requirements in $\mathrm{EE}$ program at PSU.

\section{ECE specific education}

Students are admitted into ECE programs at the beginning of the junior year but ECE courses start with freshman year, as shown in Fig. 3. Junior year has a very heavy load of ECE specific courses, which can present a shock for all students, but especially for transfer ones. Note that there are five freshman ECE courses but they only have college algebra for math prerequisites. Senior year is dominated by capstone sequence (ECE 411/412/413) and electives.

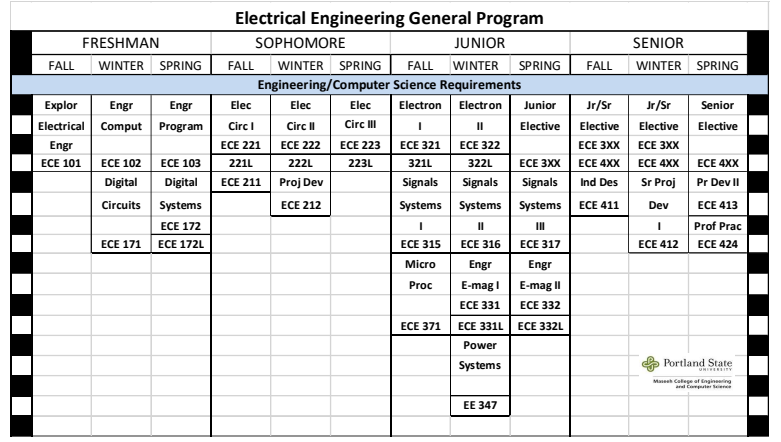

Figure 3. Outline of electrical engineering specific requirements in EE program at PSU

\section{Transfer students}

Portland State University is an urban university with a network of four nearby community colleges (CC-s), which provide students with alternative venue for finishing the lower-division engineering courses, most of the science and math coursework, and most of the general education requirements. PSU also has a dual-enrollment arrangement with community colleges which enables students to take courses simultaneously at both institutions. This arrangement benefits students by reducing cost and providing more flexibility. The downside is that it requires close collaboration between different institutions. Transition from community college to university environment can be jarring so we have to make sure that students are well prepared before transferring to PSU.

Most of our transfer students will transfer at the point of admission into program, i.e., at the start of junior year. This has created a potential problem because CC-s do not currently offer equivalents of our cornerstone courses, which means that vast majority of our transfer students will have to take them but they will already be at junior level. Furthermore, this means that instead of having only sophomore students in the cornerstone courses we also have a large number of juniors. On the one hand, this is good because such students will bring higher level of skills to their projects. On the other hand, these students have to take a large amount of other ECE courses (see Fig. 3 ), which could overload their schedules. In the future, we plan to offer special summer session of the cornerstone courses which we hope will capture most transfer students before they transfer to PSU as juniors.

One final note: Figures 1-3 illustrate our ideal program outline but due to diversity of students (age, economic 
background, academic preparation, etc.) they invariably construct their own paths. Our understanding of these pathways is limited and will require further study.

\section{SOPHOMORE CORNERSTONE COURSE}

We recently introduced our own version of a cornerstone courses at the sophomore level. The first one is ECE 211 Introduction to Design Processes, followed by ECE 212 Introduction to Project Development. We had two additional goals in mind when designing them:

1. Teach students design and project development well before they encounter them in their Capstone projects.

2. Provide an environment for experiential learning where integration of various strands of electrical and computer engineering disciplines can happen.

In our curriculum, students enrolled in ECE 211/212 will be familiar with topics such as programming, problem solving, DC circuits, and digital logic design. They should also be taking a sophomore-level circuits classes concurrently. This background should enable them to undertake more challenging technical projects.

Learning outcomes for ECE 211+212 courses can be stated as "Students will be able to:"

A. Develop requirements and specifications based on identified need.

B. Find information for the design of a product that meets customer needs.

C. Perform a functional decomposition for a given design.

D. Communicate effectively: create design log, deliver progress reports (oral or written), document product design requirements, and write a final report.

E. Implement basic project management techniques, including organizing teams and making individual contributions to overall team effort.

F. Complete and demonstrate a project that satisfies a specific need.

To accomplish these goals, we decided on developing two courses with $1+2$ credits, instead of one course. There are two main reasons for this: a) spaced practice is known to produce better learning outcomes and this is easier to accomplish over two quarters (20 weeks) than in one quarter, and b) by having a break between two courses, students are given an opportunity to refine their design proposal over the break and finalize it during the first week of the $2^{\text {nd }}$ quarter (i.e. in ECE 212).

During ECE 211 students:

1. Further develop their non-technical, professional skills, which were originally introduced at the freshman level.

2. Implement one trial run of what we call a "practicum," wherein teams of students are asked to accomplish a very specific engineering task.
3. Prepare a proposal of a project that a team will work on during ECE 212.

ECE 212 is a project-based, 10-week long course during which students work on bringing their design idea to fruition, while following the best practices established in ECE 211. The timeline for the project includes:

1. Last 3 weeks of ECE 211: Idea development and project proposal.

2. First week of ECE 212: Project is finalized.

3. Weeks 2-9: Project implemented during four 2week-long sprints.

4. Week 10: Project demos.

5. Week 11: Project documentation submitted.

Main components of our cornerstone courses are product design, teamwork, project management, integration, and each is discussed below.

\section{A. Product Design}

Most of the initial instruction and practice of design happens in ECE 211. Given that this is a 1 credit course we cannot go into great depth of the design process. Instead, we focus on:

1. Overall approach to design process,

2. identifying a need,

3. performing a high level of functional decomposition, and

4. defining product requirements.

We discuss different approaches such as humancentered design and design thinking. While the list could contain many more topics, we believe that the most important part is when students put these ideas and processes into practice. In order to stimulate their creativity, we let each team define their own product and project with only a few general requirements:

- Shall satisfy a defined need

- Shall have one or more sensors (inputs)

- Shall have one or more actuators or displays

- Shall use ESP32 microcontroler or similar

- Should use a PCB or protoboard for electronics

- Shall be well documented

If students are properly introduced to design process in ECE 211, followed by extended practice in ECE 212, then we believe that they will be much better prepared for their capstone projects.

\section{B. Teamwork}

One of the main goals of our cornerstone courses is to develop student skills in project management and teamwork (outcome E.). These are now explicitly listed as ABET requirement in Student Outcomes, criterion 5 "an ability to function effectively on a team whose members together provide leadership, create a collaborative and 
inclusive environment, establish goals, plan tasks, and meet objectives" [page 42, 4]. It can be difficult to disentangle teamwork from project management because students learn and demonstrate them together as part of a larger project. None the less, we have developed assessment for each of them separately.

Student training in teamwork happens mostly experientially, i.e., students are assigned to teams and asked to perform tasks as a team. First practice is done in ECE 211 where they are asked to perform a well-defined project and produce a working prototype over a period of two weeks. This micro project is modeled on our experience with so-called practicum project in capstone course [5].

One further learning opportunity is through collectively constructing a team contract. Within this document students describe [14]

- team procedures,

- $\quad$ team expectations, and

- consequences for failing to follow procedures and fulfill expectations.

Students construct the first contract before their practicum and refine it at the beginning of ECE 212. At this point they had first-hand experience with implementing items from their initial team contract and can make meaningful changes. Providing opportunities for revision is well known technique for improving, e.g., technical writing. However, question still remains whether constructing and improving team contracts leads to improved behavior.

\section{Project Management}

There are many ways to approach project management (PM) but there are several constraints that we need to take into account:

1. We cannot expect sophomores to do full PM of any kind, so we should design it as a step towards a more complete implementation in, for example, senior capstone course.

2. Process should be iterative so that students get to implement improvements as their project and understanding evolve.

3. It should be relatively transparent and observable to team members and instructors.

Based on our experience we believe that Scrum satisfies these criteria and can be modified to engineering education environment [15][16]. Scrum is an iterative approach to PM which allows for periodic evaluation of goals and processes used. Scrum personnel consists of Product Owner, Scrum Master, and Development Team. Scrum events include: Daily Scrum meetings, Sprint Review, Sprint Retrospective and Sprint Planning. During Scrum team produces two main artifacts: Product Backlog and Sprint Backlog [17][18]. We have used it for freshman and senior courses and have now expanded it to cornerstone courses.
In their practicum project within ECE 211 students act as Scrum Masters and there is no need to have Product Owner because project is completely defined and team only has to execute it. In ECE 212 teams work on delivering prototypes for their own designs and have to take some of the responsibilities of Product Owner. In order to provide more guidance and structure, we also hire older undergraduate students to serve as Scrum Masters. Because they have more experience, these Scrum Masters are also a good resource for technical issues but their primary role is to keep teams on track, i.e., meeting deadlines, assigning tasks, keeping documentation etc. Scrum masters provide feedback both to teams and also to instructor so that he/she can take corrective action.

To keep track of their planning and internal processes, students use two tools: Trello for sprint and day-to-day planning, and Gantt chart for project overview. Gantt chart is usually associated with waterfall PM style. We have found that students need to plan their overall activities and they have adopted Gantt chart quickly. We also allow them to modify the chart as the project progresses. Students are introduced to Trello [19] in their freshman classes, but now they have to utilize Trello for all aspects of planning and implementing their sprints.

\section{Integration}

Students in ECE 211/212 have completed a significant number of ECE courses, including programming, problem solving, digital logic, and digital systems courses. They should also be concurrently taking basic electrical circuits courses. This enables them to put together many different strands of their education as they apply them into their project. The main tool through which this happens is an ESP32 based microcontroller, such as [20]. Compared to freshman courses, students will have to write more extensive programs and use some of the more advanced features, such as IoT capabilities. Because projects require interfacing to real world, teams have to develop hardware to accomplish their goals. This is not only electronics hardware but also 3D printing of parts or cutting of materials for enclosures. This requires acquiring new skills, e.g., learning drawing programs such as Fusion 360 [21] or Solidworks [22]. Note that students have a great deal of resources at their disposal through our student-run Electronics Prototyping Lab (EPL) makerspace [23]. We believe that this component is especially relevant today as life-long learning skills and interdisciplinary experience are highly valued.

\section{EARLY OBSERVATIONS AND ASSESSMENTS}

Even though this is the first year of implementing our cornerstone courses, we can share some observations, propose improvements and discuss some assessment results.

- Our freshman problem solving course (ECE 102) and $\mathrm{C}$ programming course (ECE 103) need to provide more specific instruction on using microcontrollers. This will be done by adding lab sections to ECE 103 which will deal with basics of microcontroller programming. This will leave only some more advanced topics, such as 
communication to cloud services, to be discussed in ECE 211.

- We are still searching for more formal methods of assessing project management. PM is not a new topic but we have not been able to identify practical tools that could be used for formative and summative assessment.

- $\quad$ Based on CATME peer-rating survey tool [24], most teams function well. Less than $10 \%$ of students receive score of 3 or lower (out of 5) for their contribution to the team. CATME provides a wealth of other information that we are currently analyzing.

- We currently rely on peer assessment using CATME tool and informal observations by instructor. We need another tool to assess teamwork and we are attempting to triangulate results by using feedback from Scrum Masters. This presents two problems: a) training Scrum Masters to provide reliable and actionable feedback, and b) providing them with a rubric for this purpose. Our current rubric [16] centers on the use of Trello and does not capture well inner workings of a team.

- Using more experienced undergraduate students as Scrum Masters has worked very well and further improvements are to come from more training in the future.

- Students are warming up to using PM tools (Trello and Gantt charts) but have not fully embraced them yet.

- Among design concepts, the most confusing to students seems to be product requirements. They often confuse them with tasks that need to be completed, specific parts that need to be purchased, or, more generally, with technical specifications. However, we do not expect that all of this will become clear at this level - only that this is a stepping stone in student development.

- Among Scrum concepts, the most difficult one relates to the purpose of Scrum Retrospective. It is meant to be process oriented, i.e., how well did the team work overall, how did the internal processes work, what needs to be fixed, etc. Instead, students tend to think of it as list of technical accomplishments or failures, which are normally part of Scrum Review.

- For some tasks, such as reports at the end of each two-week long sprint, it was necessary to develop templates for the form and format of the reports. This constrains student freedom in describing various events and processes, but it was the only realistic way to process fifteen reports in a timely fashion.

- After some initial trepidation, students have come up with an intriguing and wide ranging set of products and projects, such as: UV curing chamber for 3D printed structures, automated chick hatching system, forest fire detection, automated door lock, air-quality monitor, automated control for beer brewery, water level monitor, bike charger for devices, robotic pet cat, rotating storage, package delivery detection and safe deposit, bird repellent, motorcycle tachometer and speedometer, soil monitor, and fancy doorbell. Most of these are challenging, original or both, which addresses our initial worries that students would only select easy projects.

- We need to pay special attention to schedule because many of our students work, have families or carry a heavy course load. Using CATME to set up teams helps, as does using regularly scheduled class times for daily Scrum meetings.

\section{CONCLUSIONS AND FUTURE WORK}

While we introduced many new ways to improve students' professional development in the freshman year, there was no follow up in sophomore and junior years. We believe that with two cornerstone courses described here we will fill in this gap and enhance student learning in the areas of design, teamwork, project management, and communication. We have successfully implemented Scrum approach to project management, which is now explicitly taught across three out of four years of curriculum.

Given that this is the first offering of the courses, we have much to learn but the early assessment and observations are encouraging. In order to more fully assess student learning we are either developing our own tools, such as rubrics for project management in Trello, or using existing tools, such as CATME for peer-evaluation of teamwork. In the future, we will need to pay special attention to assessment of design process and project management.

Overall, students have taken the courses seriously and have developed many original and challenging projects. We hope to continue this trend in the future.

\section{REFERENCES}

[1] National Academy of Sciences, "Rising Above the Gathering Storm: Energizing and Employing America for a Brighter Economic Future," National Academy of Sciences, Washington DC, 2007.

[2] NSF call for proposals, "IUSE/Professional Formation of Engineers: Revolutionizing Engineering Departments (IUSE/PFE: RED)," https://www.nsf.gov/funding/pgm_summ.jsp?pims_id= 505105

[3] R.M. Jones "President Obama on STEM Education," American Institute of Pysics, https://www.aip.org/fyi/2015/president-obamastem-education

[4] ABET Criteria for Accrediting Engineering Programs http://www.abet.org/wp-content/uploads/2017/12/E001-18-19EAC-Criteria-11-29-17-FINAL updated1218.pdf pp. 39-40, Accessed: 9-Apr-2018.

[5] M. Faust, A. Greenberg, and B. Pejcinovic, "Redesign of senior capstone program in electrical and computer engineering and its assessment," in 2012 Frontiers in Education Conference Proceedings, 2012, DOI: 10.1109/FIE.2012.6462390.

[6] N. W. Klingbeil and A. Bourne, "A National Model for Engineering Mathematics Education: Longitudinal Im-pact at 
Wright State University," in ASEE Annual Conference and Exhibition, Atlanta, GA, 2013.

[7] P. Wong, M. Holtzman, B. Pejcinovic, and M. ChrzanowskaJeske, "Redesign of Freshman Electrical Engineering Courses for Improved Motivation and Early Introduction of Design," in ASEE Annual Conference and Exhibition, Vancouver, Canada, 2011.

[8] B. Pejcinovic and P. Wong, "Evolution of an Introductory Electrical Engineering and Programming Course," in ASEE Annual Conference \& Exposition, Columbus, OH, 2017.

[9] D. Hall, H. Hegab, and J. Nelson. "Living with the Lab - A freshman curriculum to boost hands-on learning, student confidence and innovation," in Frontiers in Education, Saratoga Springs, NY, 2008. DOI: 10.1109/FIE.2008.4720657.

[10] G. Recktenwald, "Six Years of Living with the Lab," in ASEE Annual Conference \& Exposition, New Orleans, Louisiana, 2016. DOI: $10.18260 / \mathrm{p} .25811$

[11] D. Elzey, "Teaching Intro To Engineering In Context - UVA Engineering's New Cornerstone," in ASEE Annual Conference \& Exposition, 2006, pp. 11.1212.1-11.1212.8.

[12] K. G. Gipson, J. J. Henriques, and S. Sequeira, "Development and Implementation of a Cornerstone Course: Engineering Opportunities," in ASEE Annual Conference \& Exposition, 2015, pp. 26.509.1-26.509.19.

[13] University Studies Program, https://www.pdx.edu/unst/universitystudies-goals, Last accessed Feb. 25, 2019.

[14] Adapted from https://cns.utexas.edu/images/CNS/TIDES/teaching -portal/Team_Contract.doc, last accessed Feb. 25, 2019.
[15] R. B. Bass, B. Pejcinovic, and J. Grant, "Applying Scrum project management in ECE curriculum," in Frontiers in Education, 2016. DOI: 10.1109/FIE.2016.7757568.

[16] B. Pejcinovic, R. B. Bass, and P. Wong, "Assessing Scrum Project Management and Teamwork in Electrical and Computer Engineering Courses," in ASEE Annual Conference \& Exposition, Salt Lake City, Utah, 2018.

[17] The Scrum Guide, http://www.scrumguides.org/scrum-guide.html . Last accessed Feb. 25, 2019.

[18] K. S. Rubin, Essential Scrum: A Practical Guide to the Most Popular Agile Process, Upper Saddle River, NJ: Addison-Wesley Professional, 2012.

[19] Trello.com, Last accessed Feb. 25, 2019.

[20] Adafruit HUZZAH32 ESP32 Feather Board, https://www.adafruit.com/product/3405

[21] Autodesk Fusion 360 https://www.autodesk.com/products/fusion360/overview, last accessed Feb. 25, 2019.

[22] Solidworks https://www.solidworks.com/ , Last accessed Feb. 25 , 2019.

[23] Electronics Prototyping Lab at Portland State University, http://psu-epl.github.io/, Last accessed Feb. 25, 2019.

[24] M.W. Ohland, M.L. Loughry, D.J. Woehr, C.J. Finelli, L.G. Bullard, R.M. Felder, R.A. Layton, H.R. Pomeranz, and D.G Schmucker, "The comprehensive assessment of team member effectiveness: Development of a behaviorally anchored rating scale for self and peer evaluation," Academy of Management Learning \& Education, vo. 11, no. 4, pp. 609-630, 2012 